\title{
Characterisation of a novel virus infecting orchids of the genus Pleione
}

\author{
Petr Komínek $^{\mathrm{a}, *}$, Sébastien Massart ${ }^{\mathrm{b}}$, Khanh Pham ${ }^{\mathrm{c}}$, Paul van Leeuwen ${ }^{\mathrm{c}}$, Marcela Komínkováa \\ ${ }^{a}$ Division of Crop Protection and Plant Health, Crop Research Institute, Drnovská 507, 16106 Prague 6, Ruzynè, Czech Republic \\ ${ }^{\mathrm{b}}$ Plant Pathology Laboratory, TERRA-Gembloux Agro-Bio Tech, University of Liège, Passage des Déportés 2, 5030, Gembloux, Belgium \\ ${ }^{\mathrm{c}}$ Wageningen Plant Research, Wageningen UR, GTB Gewasgezondheid Bodem en Water, PO Box 20, 2665 ZG, Bleiswijk, the Netherlands
}

\section{A R T I C L E I N F O}

\section{Keywords:}

Pleione flower breaking virus

Potyvirus

High-throughput sequencing

Next generation sequencing

Aphid transmission

Electron microscopy

\begin{abstract}
A B S T R A C T
Plants of the genus Pleione, originating from hobby growers in the Netherlands and in the Czech Republic, were conspicuous for viral infection, showing symptoms of leaf mosaic or flower breaking. Using Sanger and high throughput sequencing, the full genome sequence of a novel potyvirus was obtained from sequencing data. The genome sequence was annotated and compared to the genome of other potyviruses. The virus was experimentally transmitted by aphids into Pleione and Chenopodium quinoa plants. The name Pleione flower breaking virus (PlFBV) was suggested for the new virus. The presence of the virus was confirmed using RT-PCR, with newly designed primers targeting this new species. The incidence of the virus was contrasted between both countries and might have been influenced by the growth conditions and the exposure of the plants to aphids.
\end{abstract}

Orchids of the genus Pleione D. Don (family Orchidaceae) are small epiphytic, lithophytic, or terrestrial orchids (Pridgeon et al., 2006). They create annual pseudobulbs with one or two leaves, usually deciduous in winter. Flowers appear either before or after the leaves, and they generally number 1-2 per plant. According to Chen et al. (2009), the genus Pleione contains about 26 species and is native to Southeast Asia. The plants have great horticultural importance because of their large flowers, ease of cultivation, and vegetative propagation (Zhu and Chen, 1998).

In 2012, a hobby orchid grower asked virology specialists at the Crop Research Institute (CRI), Prague, Czech Republic to analyse the health status of his large orchid collection of the genus Pleione. These Pleione plants showed mosaic (100\% of plants, see Fig. 2B) or flower breaking ( $5 \%$, see Supplementary Fig. 1) symptoms and were suspected to be infected by a virus. Similarly, in 2013, a hobby grower from the western Netherlands asked specialists from Wageningen University \& Research (WUR) to analyse Pleione formosana Hayata (Gibbs et al., 2000) plants cultivated in greenhouse, showing symptoms of flower breaking or streaking of the colour of the flowers (see Supplementary Fig. 2).

In such cases, identification of the viral pathogen present in diseased plants holds both scientific and agronomic interest. There are only a limited number of scientific reports on the pathogens of orchids from the genus Pleione. Only one virus species, namely Pleione virus $Y$, has been reported to infect Pleione formosana Hayata. Its genome is poorly characterized, with only one partial sequence of the coat protein (1,645 nt) available in GenBank (acc. no. AF185958). The virome of Pleione orchids is therefore poorly characterized and the presence of a new or an unexpected virus was suspected. Until recently, discovery of a novel plant virus was a long and meticulous task. The recent development of high throughput sequencing (HTS) technologies, also called Next Generation Sequencing (NGS), has provided a powerful alternative for their detection and identification without any a priori knowledge. The nucleic acids extracted from the plants can be sequenced at very high throughput, allowing potentially the identification of any virus present in the plant and the sequencing of its full or nearly full genome (Massart et al., 2014).

Therefore, the whole genome of an unknown virus can be sequenced by HTS technologies, but, at this stage, there is no information on the biological significance of this new species - with nothing being known about its particle structure, pathogenicity, host range, transmission, prevalence, epidemiology, etc. Therefore, the application of HTS technologies should be completed by the genome annotation followed by a biological characterisation of the newly identified virus using classical methodologies. As it can be a long and complex process, a framework for progressive characterisation has recently been proposed (Massart et al., 2017) in order to prioritize the efforts and the focus.

This paper describes the characterization of a novel potyvirus identified in diseased Pleiones from two countries through observation of viral particles, sequencing of its full genome by HTS technologies and

\footnotetext{
Abbreviations: HTS, high throughput sequencing; PlFBV, Pleione flower breaking virus; KjMV, Keunjorong mosaic virus

* Corresponding author.

E-mail address: kominek@vurv.cz (P. Komínek).
} 
Table 1

High throughput sequencing results from Pleione plants. Genome coverage was calculated by Geneious.

\begin{tabular}{|c|c|c|c|c|c|}
\hline Sample (cultivar) & Number of unique reads & Virus & Number of mapped virus reads & Genome coverage in $\%$ & Genome sequencing depth \\
\hline Wharfedale & $4,415,108$ & PlFBV & 124,054 & 99.99 & $1871 \mathrm{X}$ \\
\hline Shasta & $7,640,276$ & PlFBV & 26,819 & 99.8 & $403 x$ \\
\hline Slender Loris & $1,056,330$ & PlFBV & 33,914 & 99.6 & $509 x$ \\
\hline
\end{tabular}

Sanger and its preliminary biological characterisation.

For the identification of the agent present in symptomatic Pleiones, electron microscopy was used to reveal any viral particles present in the plant's sap. Plant leaves with symptoms were homogenized with $4 \%$ phosphotungstic acid ( $\mathrm{pH}$ 6.9) at a ratio of approximately 1:5. A small droplet was taken from the homogenate, and formvar coated grids were placed into the droplet for $20 \mathrm{~s}$. The grids were then removed, and any excess of the homogenate was carefully removed by a piece of filtration paper. After air drying, the grids were then examined by a Philips EM $208 \mathrm{~S}$ transmission electron microscope, operating at $70 \mathrm{kV}$. Images were taken with a Veleta digital camera (Olympus, Hamburg, Germany) and processed using iTEM software (EMSIS, Muenster, Germany).

As a result, filamentous particles were observed (see Supplementary Fig. 3) in the sap of symptomatic Pleiones. The modal length of these particles was $720 \mathrm{~nm}$.

As the observed particles were resembling those of potyviruses, RTPCR approach was used in the virology laboratory of WUR Wageningen to amplify the $3^{\prime}$ terminal region with a potyvirus-specific degenerate primers in combination with an oligo-dT reverse primer (Langeveld et al., 1991). The primers were used according to the mentioned work, PCR product was directly sequenced. Obtained sequence was analysed using web-based BLAST, showing it belongs to a novel virus. It was tentatively named Pleione flower breaking virus, acronym PlFBV, according its host and major symptoms. The sequence of $1,367 \mathrm{bp}$ length was submitted into GenBank under acc. no. KF360240.1. To obtain fulllength sequence of the novel virus, high throughput sequencing was applied.

RNA was isolated from symptomatic Pleiones, using a mirVana miRNA isolation kit (ThermoFisher Scientific, Waltham, MA, USA), according to the manufacturer's instructions, starting with $1 \mathrm{~g}$ of plant material. RNA quality was assessed by an Agilent 2100 Bioanalyzer (Agilent Technologies, Santa Clara, CA, USA). On the basis of quality measuring, three RNA samples with highest quality were selected for HTS. They originated from Czech Republic and corresponded to symptomatic Pleione hybrids named Wharfedale, Shasta, and Slender Loris. Ribosomal RNA was removed using a RiboMinus Plant Kit for RNA-Seq (ThermoFisher Scientific, Waltham, MA, USA). Total RNA libraries were then prepared using a simplified protocol (no enrichment in poly-A RNA) with a TrueSeq Stranded mRNA kit (Illumina, San Diego, CA, USA). More precisely, ribodepleted RNA entered the process at point 12 of the manufacturer's instructions; a "Make RFP" chapter, and only Fragment, Prime, Finish mix was added. All further steps were performed according to the instructions.

Libraries were prepared at both CRI Prague (Pleione cultivar Slender Loris) and the GIGA sequencing centre of Liège University in Belgium (cultivars Wharfedale and Shasta). The libraries were sequenced using a MiSeq machine in the BIOCEV centre in Vestec, Czech Republic (Slender Loris), and on a Nextseq 500 sequencing machine at Liège University in Belgium (Wharfedale and Shasta); all three for $2 \times 150 \mathrm{nt}$.

Data obtained from the 3 samples were analysed using Geneious software, version 11.0.4. (Biomatters, Auckland, New Zealand). Duplicated reads were first eliminated. De novo assembling was done using a Geneious assembler with the following parameters: word length 21 , maximum mismatches per read $10 \%$, minimum overlap identity $92 \%$, index word length 14 , re-analyse threshold 16 , maximum ambiguity 16 . De novo contigs were annotated using the TBLASTX module of Geneious for homology with a local database of viruses and viroids downloaded from the RefSeq database of NCBI. The contigs with a viral hit were further analysed. Mapping unique reads into reference sequences were done using a Geneious mapper with the following parameters: fine tuning none (fast read mapping), minimum mapping quality 30 , word length 17 , maximum mismatches per read $2 \%$, do not allow gaps, minimum overlap identity $98 \%$, index word length 9 , maximum ambiguity 16 , search more thoroughly for poor matching reads set to yes.

Different numbers of unique reads were obtained from individual samples (see Table 1). After de novo assembly, the contigs were annotated as described. In all three samples, one of the largest obtained contigs (length of $c a$. 9,900 bp) appeared to be an almost full-length genome of PlFBV. There was no other plant virus present in the analysed data, either known or unknown. The genome of the PlFBV was assembled after mapping reads back to the longest contig. The $5^{\prime}$ and $3^{\prime}$ ends of the PlFBV genome were sequenced by RACE, using a $5^{\prime} / 3^{\prime}$ RACE Kit, 2nd Generation (Roche, Basel, Switzerland).

Table 1 shows the results of mapping reads to the full length of PlFBV, as obtained after RACE. The genome sequencing depth was high: 403X, 509X and 1,871 X. In the three samples the genome coverage reached almost $100 \%$ of the complete genome sequence.

Sequencing depth was calculated as number of unique mapped reads * length of reads / length of virus genome, this represent the average coverage of each base by sequencing reads.

The three full-length genome sequences of PlFBV and the partial PlFBV genome sequence from Netherlands were very similar to each others with a total of 20 divergent positions between isolates (see Supplementary Table 1). The full-length sequence of PlFBV from the Pleione hybrid Wharfedale was submitted into GenBank under acc. no. MH376747. The PlFBV genome is 9,940 nt long, excluding the polyadenylated 3 ' end.

A large ORF, typical in potyviruses, was identified using the Geneious ORF finder. It is located between nucleotide positions 94 and 9,774 . The genomic $5^{\prime}$ non-coding region is $93 \mathrm{nt}$ long; and the $3^{\prime}$ noncoding region is $166 \mathrm{nt}$ long, excluding the polyadenylated end. A further short ORF placed inside the P3 gene, called PIPO (pretty interesting Potyviridae ORF) and described by Chung et al. (2008), was found starting in position 3,321, just after conserved motif GGAAAAAA, which serves as a "slippery site" for -1 frameshift. The PIPO is 231 nucleotides long ( $=77$ amino acids). The stop codon TAA for the PIPO ORF occurs in position 3,552 . The large polyprotein is probably subsequently cleaved, as in the case of other potyviruses. We performed an

Table 2

PlFBV proteins - size, cleavage sites, and comparison to KjMV.

\begin{tabular}{llll}
\hline Protein & Length (aa) & $\begin{array}{l}\text { Cleavage site at the } \\
\text { end }\end{array}$ & $\begin{array}{l}\text { Amino acid identity with } \\
\text { KjMV (\%) }\end{array}$ \\
\hline P1 & 465 & TRHF/S & 44 \\
HCPro & 455 & YKVG/G & 68 \\
P3 & 346 & VRLQ/N & 53 \\
6K1 & 52 & VRPQ/S & 81 \\
CI & 634 & VRLQ/G & 78 \\
6K2 & 53 & VVHQ/G & 60 \\
VPg & 189 & VRQE/G & 62 \\
NIa - Pro & 242 & VFEQ/A & 73 \\
Nib & 521 & VCLQ/A & 72 \\
CP & 270 & & 71 \\
whole polyprotein & 3227 & & 70 \\
\end{tabular}




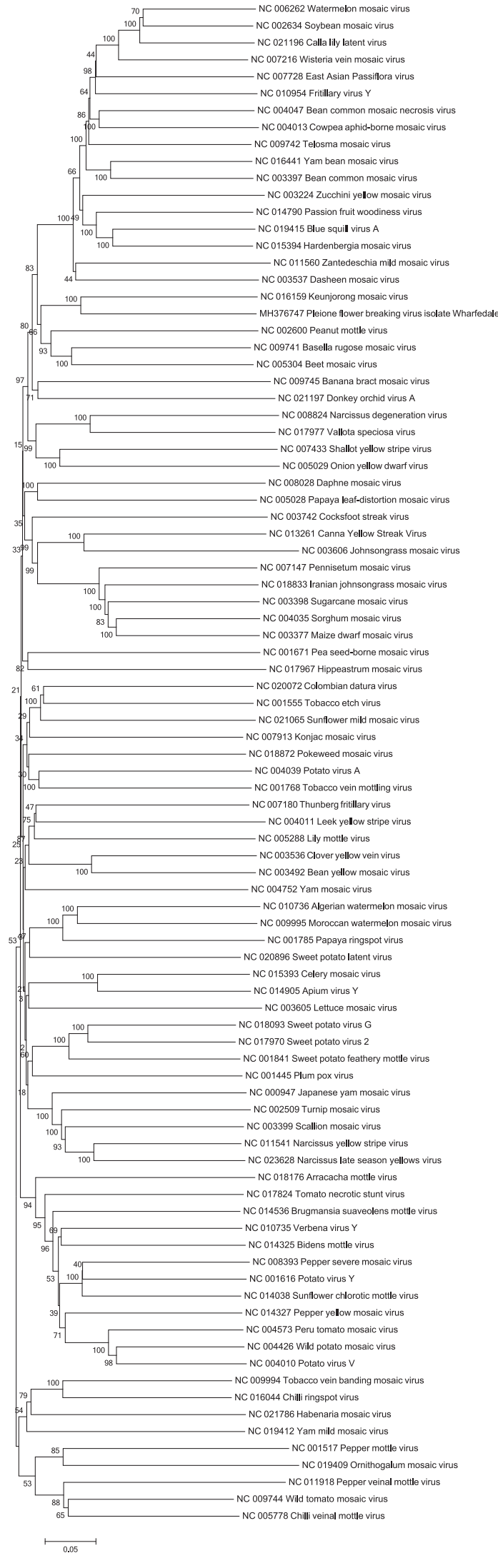

analysis of tentative cleavage sites of individual proteins within its amino acid sequence using the web page http://www.dpvweb.net/ potycleavage/index.html. Identified cleavage sites are listed in a
Fig. 1. Phylogenetic analysis of the polyprotein coding sequences of important members of the genus Potyvirus, showing the position of the Pleione flower breaking virus (highlighted in yellow) inside the genus. The evolutionary history was inferred using the Neighbor-Joining method using MEGA7 (Kumar et al., 2016), and the optimal tree is shown. The numbers next to the branches represent the percentage of replicated trees according to the bootstrap test (500 replicates). The evolutionary distances were computed using the p-distance method (For interpretation of the references to colour in this figure legend, the reader is referred to the web version of this article).

Table 2. The P1/HC-Pro cleavage site was identified at a position similar to other species of the genus Potyvirus but presented a unique recognition sequence (TRHF/S) (see Supplementary Figures 4 and 5, and Supplementary File 1).

The DAG triplet, located near the $\mathrm{N}$ end of the $\mathrm{CP}$ gene, which is considered responsible for potyvirus aphid transmissibility (Atreya et al., 1990), was found starting at nt position 8986 of the full virus sequence.

To confirm the assignation of Pleione flower breaking virus into the genus Potyvirus, phylogenetic analysis using the MEGA7 program (Kumar et al., 2016) was conducted. The nucleotide sequence of entire ORF of ninety members of the genus Potyvirus was compared and aligned using ClustalW embedded in MEGA7. The Neighbor-Joining method was used for the evolutionary analysis, and bootstrap was calculated from 500 replicates (Fig. 1). The analysis confirmed the position of PlFBV inside the genus Potyvirus.

To compare two viruses infecting plants of the genus Pleione, we made further phylogenetic analysis, based only on the coat protein gene, and including Pleione virus Y. The resulting tree is available as Supplementary Fig. 6, and it reveals that the two Pleione-infecting viruses are not related. Instead, PlFBV clustered together with another potyvirus, Keunjorong mosaic virus (Nam et al., 2013), which has been described as infecting Cynanchum wilfordii (Maxim.) Hemsl. that is a perennial shrub belonging to the family Asclepiadaceae, occurring in East Asia where it is important in traditional medicine (Lee et al., 2018; Jiang et al., 2018). PlFBV and KjMV protein sequences were also compared. The amino acid identities of individual proteins of the two viruses ranged from $44 \%$ in the case of the P1 protein, to $81 \%$ in the case of $6 \mathrm{~K} 1$. Overall amino acid identity was $70 \%$ (see Table 2). This further confirms the difference between PlFBV and KjMV, showing that they are two different virus species; as the criteria given by ICTV put a threshold for species demarcation to $58 \%$ amino acid identity for the P1 region, and $82 \%$ for the entire polyprotein (Wylie et al., 2017).

In addition, a RT-PCR protocol was developed to detect PlFBV in Pleione plants. The primers were designed using Primer3Plus (Untergasser et al., 2007) with the default parameters. Their sequences are $5^{\prime}$ CCGTCCATCATCGTCCAAAC 3' (antisense primer) and 5' ATC GCTCAACTGAAATCGCC $3^{\prime}$ (sense primer), expected product length was 703 nucleotides. They were placed on the CP gene and they were also checked by NCBI BLAST to ensure their specificity. To detect the virus, RNA was isolated from 30 plants of the Pleione collection from the Czech Republic, using a Spectrum ${ }^{\mathrm{TM}}$ Plant Total RNA Kit (SigmaAldrich, St. Louis, MO, USA). Subsequently, reverse transcription was performed with a Transcriptor First Strand cDNA Synthesis Kit (Roche, Basel, Switzerland), using random hexamers for reaction priming according to the manufacturer's directions. For PCR, the FastStart Taq DNA Polymerase (Roche, Basel, Switzerland) was used. The reaction conditions were as follows: $95^{\circ} \mathrm{C} / 5 \mathrm{~min}, 40 \times\left(95^{\circ} \mathrm{C} / 35 \mathrm{~s}, 64^{\circ} \mathrm{C} / 40 \mathrm{~s}\right.$, $\left.72{ }^{\circ} \mathrm{C} / 55 \mathrm{~s}\right), 72^{\circ} \mathrm{C} / 7 \mathrm{~min}$. As expected, the product of the reaction was 703 bp (see also Supplementary Fig. 7) and the PlFBV was detected in all 30 tested plants.

Further, aphid transmission experiments with PlFBV were conducted. All plants used for transmission experiments were previously tested by the designed RT-PCR protocol to ensure they are not infected before the inoculation (see also Supplementary Fig. 7). Young aphids Myzus persicae Sulz., reared at CRI Prague, were placed onto 

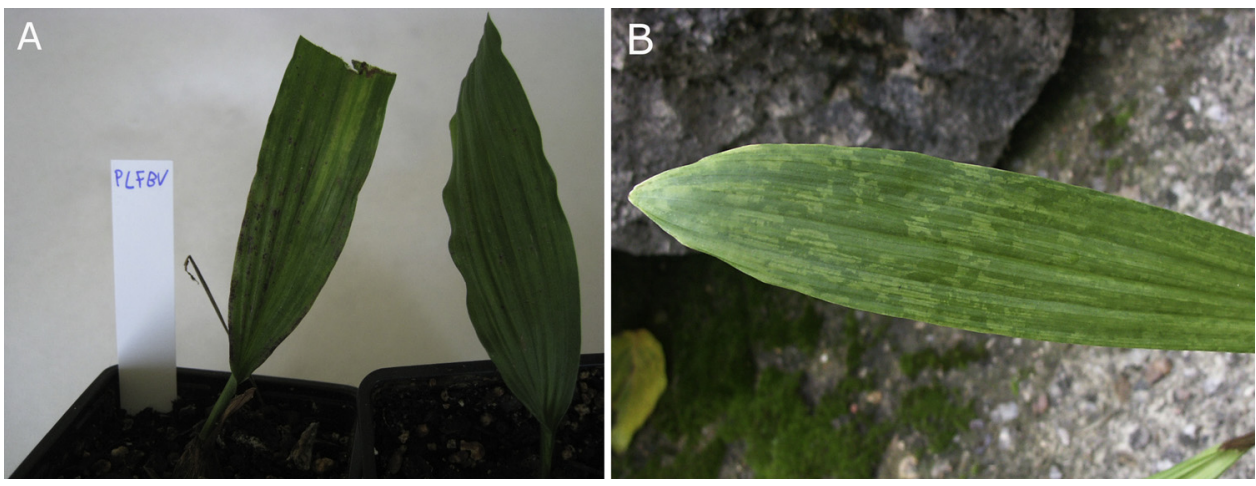

Fig. 2. Symptoms of virus infection on leaves of Pleione plants.

A) Mosaic symptoms on Pleione formosana Hayata after artificial infection by aphids (left) compared with a healthy plant (right).

B) Mosaic symptoms on a leaf of the Pleione hybrid Christianii.

symptomatic leaves of Pleione hybrids Wharfedale and Shasta. After 5-10 min of acquisition feeding, they were carefully transferred manually to young plants of Chenopodium quinoa Willd., Nicotiana benthamiana Domin, and Nicotiana clevelandii Gray x N. glutinosa L. (10 plants per species), as well as to three plants of Pleione formosana Hayata purchased in a market. At least 50 aphids were used per every inoculated plant to ensure successful virus transmission.

The inoculated herbaceous plants showed no symptoms after aphid inoculation. However, plants of Chenopodium quinoa Willd., inoculated by aphids from plants of Pleione x Shasta, were positive by RT-PCR for PlFBV, when tested 5 weeks after transmission (see also Supplementary Fig. 7). Sequencing of the PCR product confirmed the identity with PlFBV genome (data not shown). Electron microscopy examination also revealed the presence of filamentous virus particles in the Chenopodium quinoa Willd. plants (picture not shown).

Three aphid inoculated Pleione formosana Hayata plants showed symptoms of mosaic 5 weeks after transmission (see Fig. 2A). The presence of the PIFBV was also confirmed by RT-PCR (Supplementary Fig. 7). Three non-inoculated plants showed no symptoms. Aphid transmission is the main mode of potyvirus transmission, and PlFBV is no exception as was proven by our experiment.

Concerning virus incidence, in the Netherlands the diseased plants were removed and the years afterwards no more disease symptoms were observed. One putative reason is the location of the Pleiones in a greenhouse, which might have prevented or limited the presence of aphid vectors. On the other hand, the virus prevalence in the Pleione collection from the Czech Republic was $100 \%$. This might be related to the grower's practice growing the plants in open air during summer months, where they are freely accessible to aphids.

We can conclude that a distinct member of the genus Potyvirus, family Potyviridae, was found infecting plants of the genus Pleione. Its entire genome sequence has been characterized, and also its transmissibility by aphids has been demonstrated. We suggest the name Pleione flower breaking virus, and the PlFBV acronym for this virus.

\section{Funding}

Part of this work was based upon COST Action FA1407 (DIVAS), supported by COST (European Cooperation in Science and Technology).

This work was supported by institutional support MZE-RO0418 from the Ministry of Agriculture of the Czech Republic.

\section{Conflicts of interest}

The authors declare that they have no conflicts of interest.

\section{Acknowledgements}

The authors wish to thank Mrs. Miloslava Ducháčová (CRI Prague) for her skilled technical assistance, especially with electron microscopy.

The authors thank to Karel Týbl for valuable comments concerning growing of Pleiones.

\section{Appendix A. Supplementary data}

Supplementary material related to this article can be found, in the online version, at doi:https://doi.org/10.1016/j.virusres.2018.12.009.

\section{References}

Atreya, C.D., Raccah, B., Pirone, T.P., 1990. A point mutation in the coat protein abolishes aphid transmissibility of a potyvirus. Virology 178, 161-165.

Chen, X., Cribb, P.J., Gale, S.W., 2009. Pleione D. Don. Flora China 25, 325-333.

Chung, B.Y.W., Miller, W.A., Atkins, J.F., Firth, A.E., 2008. An overlapping essential gene in the Potyviridae. Proc. Natl. Acad. Sci. U. S. A. 105 (15), 5897-5902.

Gibbs, A., Mackenzie, A., Blanchfield, A., Cross, P., Wilson, C., Kitajima, E., Nightingale, M., Clements, M., 2000. Viruses of orchids in Australia; their identification, biology and control. Aust. Orchid Rev. 65, 10-21.

Jiang, H.W., Lin, J., Wang, G.M., Zhang, J.J., Gu, S.S., Cao, L., Chen, Y., Wang, L., Jiao, H., Zhu, W.L., Zhang, H.Y., Zhao, W.M., Li, J.L., 2018. Acetophenone derivatives from the root bark of Cynanchum wilfordii as potential neuroprotective agents. Phytochem. Lett. 24, 179-183.

Kumar, S., Stecher, G., Tamura, K., 2016. MEGA7: molecular evolutionary genetics analysis version 7.0 for bigger datasets. Mol. Biol. Evol. 33, 1870-1874.

Langeveld, S.A., Dore, J.-M., Memelink, J., Derks, A.F.L.M., van der Vlugt, C.I.M., Asjes, C.J., Bol, J.F., 1991. Identification of potyviruses using the polymerase chain reaction with degenerate primers. J. Gen. Virol. 72, 1531-1541.

Lee, H., Kim, M.H., Choi, Y.Y., Hong, J., Yang, W.M., 2018. Effects of Cynanchum wilfordii on osteoporosis with inhibition of bone resorption and induction of bone formation. Mol. Medic. Reports 17, 3758-3762.

Massart, S., Olmos, A., Jijakli, H., Candresse, T., 2014. Diagnosis of viral and high throughput sequencing: towards a paradigm shift? Virologie 18, 247-250.

Massart, S., Candresse, T., Gil, J., Lacomme, C., Predajna, L., Ravnikar, M., Reynard, J.-S., Rumbou, A., Saldarelli, P., Škorić, D., Vainio, E.J., Valkonen, J.P.T., Vanderschuren, H., Varveri, C., Wetzel, T., 2017. A framework for the evaluation of biosecurity, commercial, regulatory, and scientific impacts of plant viruses and viroids identified by NGS technologies. Front. Microbiol. 8, 45.

Nam, M., Lee, J.H., Choi, H.S., Lim, H.S., Moon, J.S., Lee, S.H., 2013. Complete genome sequence of keunjorong mosaic virus, a potyvirus from Cynanchum wilfordii. Arch. Virol. 158, 1817-1820.

Genera orchidacearum volume 4. In: Pridgeon, A.M., Cribb, P.J., Chase, M.W., Rasmussen, F.N. (Eds.), Epidendroideae (Part One). Oxford University Press, Oxford, pp. 696.

Untergasser, A., Nijveen, H., Rao, X., Bisseling, T., Geurts, R., Leunissen, J.A.M., 2007 Primer3Plus, an enhanced web interface to Primer3. Nucleic Acids Res. 35, W71-W74.

Wylie, S., Adams, M., Chalam, C., Kreuze, J., López-Moya, J., Ohshima, K., Praveen, S., Rabenstein, F., Stenger, D., Wang, A., Zerbini, F., ICTV Report Consortium, 2017. ICTV virus taxonomy profile: potyviridae. J. Gen. Virol. 98 (3), 352-354.

Zhu, G.H., Chen, S.C., 1998. Humiles, a new section of Pleione (Orchidaceae). Novon 8, $461-463$. 